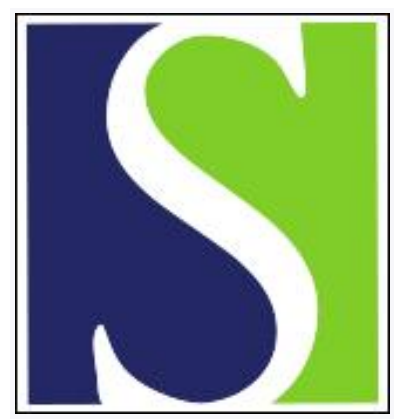

Scand J Work Environ Health 2001;27(2):106-112

https://doi.org/10.5271/sjweh.596

Issue date: Apr 2001

High-resolution computed tomography classification of lung fibrosis for patients with asbestos-related disease

by Huuskonen $\mathrm{O}$, Kivisaari L, Zitting A, Taskinen K, Tossavainen A, Vehmas T

Affiliation: Finnish Institute of Occupational Health, Topeliuksenkatu 41 a A, FIN-00250 Helsinki, Finland. Olli.Huuskonen@occuphealth.fi

Refers to the following text of the Journal: 1998;24(2):109-117

The following article refers to this text: 2004;30(3):206-214

Key terms: asbestos-related disease; asbestosis; high-resolution computed tomography; high-resolution computed tomography classification; HRCT; ILO classification; kappa; lung fibrosis; observer variation; occupational disease; patient; pneumoconioses; receiver operating characteristic curve

This article in PubMed: www.ncbi.nlm.nih.gov/pubmed/11409592 


\title{
High-resolution computed tomography classification of lung fibrosis for patients with asbestos-related disease
}

\author{
by Olli Huuskonen, MD, ${ }^{1}$ Leena Kivisaari, MD, ${ }^{2}$ Anders Zitting, MD, ${ }^{1}$ Kristian Taskinen, MSc, ${ }^{1}$ \\ Antti Tossavainen, DTechn, ${ }^{1}$ Tapio Vehmas, $M D^{1}$
}

\begin{abstract}
Huuskonen 0, Kivisaari L, Zitting A, Taskinen K, Tossavainen A, Vehmas T. High-resolution computed tomography classification of lung fibrosis for patients with asbestos-related disease. Scand J Work Environ Health 2001;27(2):106-112.
\end{abstract}

Objectives This study tested a new high-resolution computed tomography (HRCT) scoring method for asbestos-induced parenchymal changes in the lung.

Methods HRCT scans of 602 asbestos-exposed workers and 49 referents were reviewed by 3 radiologists. Structured forms were filled out for a semiquantitative HRCT fibrosis score based on several specified parenchymal abnormalities scored separately. Observer agreement was studied with the use of the quadraticweighted kappa $\left(\kappa_{\mathrm{qw}}\right)$. The HRCT fibrosis score (from 0 to $\mathrm{V}$ with definitions and index images given retrospectively) was compared with the radiographic classification of the International Labour Office (ILO) for the same patients. Receiver-operating characteristic (ROC) curves were computed to compare the tests for diagnosing asbestosis.

Results Good inter- and intraobserver agreements were achieved ( $\kappa_{\mathrm{qw}}=0.64$ and 0.72 , respectively) as regards the HRCT fibrosis score. All the specified computed tomography findings explained $86 \%$ of the variance in the HRCT fibrosis score. Age and occupational group were significant predictors of fibrosis. The area under the ROC curve was significantly greater for the HRCT fibrosis score (0.89) than for the ILO radiographic classification (0.76). The sensitivity (70\%) and specificity $(91 \%)$ of the HRCT fibrosis score (classes I/II-V representing asbestosis) were better than those of the classification published by the International Labour Office ( $51 \%$ and $89 \%$, respectively, score $\geq 1 / 0$ representing asbestosis).

Conclusions The examined HRCT scoring method proved to be a simple, reliable, and reproducible method for classifying lung fibrosis and diagnosing asbestosis also in large populations with occupational disease, and it would be possible to use it as a part of an international classification.

Key terms asbestosis, ILO classification, kappa, observer variation, occupational diseases, receiver operating characteristic curve.

For many decades the International Labour Office (ILO) classification of radiographs of pneumoconioses (1) has been the gold standard used in the radiological evaluation of asbestos-induced lung fibrosis (2). Although the method was originally supposed to be used for epidemiologic purposes only, it has attained an important position also as a diagnostic tool along with clinical investigation, pulmonary function tests, and lung histopathology, when available. For a single patient, the ILO classification system has a severe handicap due to its low sensitivity in the early stages of fibrosis (3). Diagnosing interstitial fibrosis from radiographic findings also gives a considerable amount of false positive results because small opacities may occur in radiographs without fibrosis (4) and radiographs with marginal abnormalities may be interpreted as pathological because of the great observer variation (5). Although asbestosis is incurable, patients are entitled to financial compensation for it as an occupational disease. The exact knowledge of the presence or absence of asbestosis is therefore essential.

Since the late 1980s, computed tomography (CT) and especially thin-section high-resolution CT (HRCT) have proved to be much more sensitive in detecting

1 Finnish Institute of Occupational Health, Helsinki, Finland.

2 Helsinki University Central Hospital, Department of Radiology, Helsinki, Finland.

Reprint requests to: Dr Olli Huuskonen, Finnish Institute of Occupational Health, Topeliuksenkatu 41 a A, FIN-00250 Helsinki, Finland. [E-mail: Olli.Huuskonen@occuphealth.fi] 
asbestos-induced pleural and parenchymal changes in their early stages (6-11), even before clinical signs are present (12-14). With the new technologies it may be difficult to separate between subnormal radiological findings that can occur in a normal elderly population and the significant ones possibly due occupational exposure. Even though the correlation between typical HRCT findings and lung pathology has already been well established (15-17) and HRCT is widely used to diagnose and follow the progression of asbestosis, there is marked heterogeneity in the clinical and radiological protocols used in the imaging and classification of fibrosis $(9,10,17-22)$. There is no internationally accepted and widely used classification system.

Our institute has had an asbestos program since 1987, and this program has aimed at minimizing all exposure to asbestos, identifying people exposed occupationally, and improving the diagnostics of asbestos-related diseases. The work is done in co-operation with government authorities, industry, trade unions, health care services, insurance companies, and the mass media. The aim of this study was to develop a new scoring method for asbestos-induced lung abnormalities with HRCT and CT and to test its reliability for both epidemiologic and diagnostic purposes.

\section{Subjects and methods}

\section{Exposed workers}

In a previous study of 18900 Finnish persons exposed to asbestos, 2857 were identified as having an asbestosrelated occupational disease (4). Those living in the Helsinki area $(\mathrm{N}=642)$ and willing to participate $(\mathrm{N}=602)$ were included in this study. The study group consisted of 591 men and 11 women, their mean age being 64 (range 38-81) years. Most of these persons had been occupationally exposed to asbestos for $>20$ (mean 26) years and had smoked 24 pack-years on an average. There were 85 patients with diagnosed asbestosis and 601 with bilateral pleural plaques in chest radiography. For the latter patients without asbestosis, a history of smoking for $\leq 10$ years was also an inclusion criterion.

Occupational physicians personally interviewed the patients with the use of a standardized questionnaire, which included questions on the patients' smoking habits and occupational history. The patients were then classified into 6 categories by their main occupation and numbered according to estimated increasing asbestos exposure (figure 1, groups 3-8). All the enrolled patients were construction workers who had installed heat and fire insulation, walls, and ceiling panels containing asbestos or had used asbestos paints, putties, and fillers. Some of them had dismantled asbestos-containing materials or cleaned construction sites where asbestos was present.

\section{Referents}

Fifty willing persons were originally collected to form the unexposed reference group. They were submitted to chest $\mathrm{CT}$ at a university hospital due to suspicion of or control for an extrathoracic malignancy. All the referents were men. Their mean age was 61 (range 50-75) years, and they had all smoked for $>10$ years. The referents were screened for pulmonary metastases, and 1 person was excluded later due to such a finding. Other exclusion criteria were asbestos exposure reported in a brief interview prior to the $\mathrm{CT}$ examination and previous anticancer drug therapy, due to its potential to induce lung fibrosis.

In a detailed retrospective interview by an occupational physician, however, potential exposure to asbestos could not be ruled out in 30 of the 49 cases, because of work in the construction industry (4 cases) or in a shipyard ( 2 cases) for several years, very limited exposure either occupationally or leisurely, or nonavailability for interview. These persons formed group 2 (figure 1). Nineteen persons who had probably no asbestos exposure formed group 1.

\section{Imaging}

Unenhanced spiral CT was performed with a Picker PQ 2000 scanner (Picker International, United States) in the supine position and full inspiration from the apical lungs to the costophrenic angle $(125 \mathrm{~mA}, 140 \mathrm{kV}$, collimation $10 \mathrm{~mm}$, pitch 1.5). The images were reconstructed with a 10-mm slice thickness using a standard algorithm. The images were printed at settings appropriate for viewing the lung parenchyme [window width 1000 Hounsfield units (HU), window level $-700 \mathrm{HU}]$ and the mediastinum and pleura (WW $400 \mathrm{HU}, \mathrm{WL} 40 \mathrm{HU}$ ). In addition, 4-7 HRCT slices were exposed from the aortic arch or pulmonary hila to the lung bases $(200 \mathrm{~mA}$, $130 \mathrm{kV}, 1.5 \mathrm{~mm}$ slices, WW $1000 \mathrm{HU}, \mathrm{WL}-700 \mathrm{HU}$ ).

The referents were imaged (contrast enhanced spiral CT, 10-mm slices, imaging settings according to the clinical indication) at the University Central Hospital with a Siemens Somatom Plus S or Somatom Plus 4 scanner (Siemens AG Medical Engineering Group, Germany). Four extra HRCT slices (1-mm thickness) were exposed due to this study with the patients' informed consent and the permission of the local ethics committee.

Standard chest radiographs in posteroanterior and lateral positions were also taken of all the exposed workers. 
These images were used to study the correlation between the HRCT findings and the findings in the chest radiographs and the performance of the 2 methods in diagnosing asbestosis.

\section{Image analysis}

All the images were reviewed by 3 experienced radiologists (LK, TV, AZ) separately. The readers were blinded to all the clinical information, except for the patients' names and ages, which were printed on the images. Each observer double-read a set of 43 (HR)CT examinations to estimate intraobserver agreement. The interval between the 2 subsequent readings was $\geq 1$ month. A structured form on lung abnormalities was filled out at each reading. The form was modified from an earlier classification system published by Oksa et al (10). Fibrosis was scored using an arbitrary semiquantitative scale from 0 to V (HRCT fibrosis score later in this article) including 1 subclass between each class (eg, II/ III). Several specified abnormalities were also scored on an arbitrary scale from 0 to 5 (for findings for which meticulous differentiation is not possible, from 0 to 3 ) where 0 represents no change and 5 (or 3) maximal changes. The system was used to classify the following abnormalities in both lungs separately: subpleural dependent opacity, subpleural curvilinear opacities, subpleural perpendicular lines, parenchymal bands, subpleural nodules, honeycombing, and ground glass opacities. Two other variables, which were not components of interstitial fibrosis, were calculated on the basis of other findings in the filled out forms: "emphysema", consisting of centrilobular, paraseptal, panlobular emphysema and bullae, and "other disease", consisting of bronchiectasies, other local fibrosis and signs of other parenchymal disorders.

Of all the 602 chest radiographs, 281 enriched with pulmonary and pleural abnormalities in the (HR)CT were selected by a statistician to be classified according to the ILO 1980 classification. The radiographs were classified separately by 2 radiologists (TV and AZ, the latter being a certified NIOSH "B" reader), who were blinded from all the clinical information and findings in the CT and HRCT, except for the patients' names and ages, which were shown on the images.

\section{Statistical analysis}

The pooled inter- and intraobserver agreement for all 3 observers with respect to the pertinent lung abnormalities was computed using the quadratic-weighted kappa $\left(\kappa_{\mathrm{qw}}\right)$, which represents intraclass correlation. The interobserver agreement between the 2 readers was calculated also for the ILO classification. After the kappa coefficients were computed, the mean values of the radi- ologists' scores were used in additional computations. The radiological findings explaining the HRCT fibrosis score were analyzed by multivariate linear regression. Age, gender, smoking habits (pack-years), and occupations were compared with the HRCT fibrosis score using an analysis of covariance (ANCOVA). These analyses yielded coefficients of determination $\left(\mathrm{r}^{2}\right)$ that represented the proportion of the variance explained by the model.

To assess the value of the scoring system in diagnosing asbestosis, a receiver operating characteristic (ROC) analysis was performed. The test yields a threshold value for the HRCT fibrosis score or the ILO score that would best separate patients with asbestosis from other exposed workers, and it gives the specificity and sensitivity of the test at specified cut-off points (23). The areas under the 2 ROC curves (representing the HRCT and ILO scores) were compared using the following $\mathrm{z}$ test equation described by Hanley \& McNeill (24):

$$
\mathrm{z}=\frac{\mathrm{A}_{1}-\mathrm{A}_{2}}{\sqrt{\mathrm{SE}_{1}^{2}+\mathrm{SE}_{2}^{2}-2 \mathrm{rEE}_{1} \mathrm{SE}_{2}}},
$$

where $A_{1}$ and $A_{2}$ stand for the areas under the curves and $\mathrm{SE}_{1}$ and $\mathrm{SE}_{2}$ represent their standard errors, and $\mathrm{r}$ is derived from the correlation between the 2 methods (described in detail in the aforementioned article). The test statistic ( $\mathrm{z}$ ) indicates the area under the normal curve and is easily transformed to a P-value using statistical tables or programs.

The correlation of the HRCT fibrosis score and the ILO profusion score of chest radiographs was tested with Spearman's rank correlation $(\rho)$. A nonparametric regression analysis was performed for the 2 classifications using an abbreviated Theil method (25).

All the statistical analyses were computed using SPSS (Version 9.0, SPSS Inc, Chicago, Illinois, United States), the SAS System (SAS Institute, Cary, North Carolina, United States) and PEPI (23) software.

\section{Results}

\section{Agreement}

The intraobserver agreement was higher than the interobserver agreement for almost all the variables. All the $\kappa_{\mathrm{qw}}$ values describing agreement were positive and differed significantly from 0 (table 1 ).

\section{High-resolution computed tomography fibrosis score}

The correlation coefficients between the specified HRCT findings and the HRCT fibrosis score are listed in table 2 . When all 9 variables were analyzed with a linear regression, the proportion of variance explained 


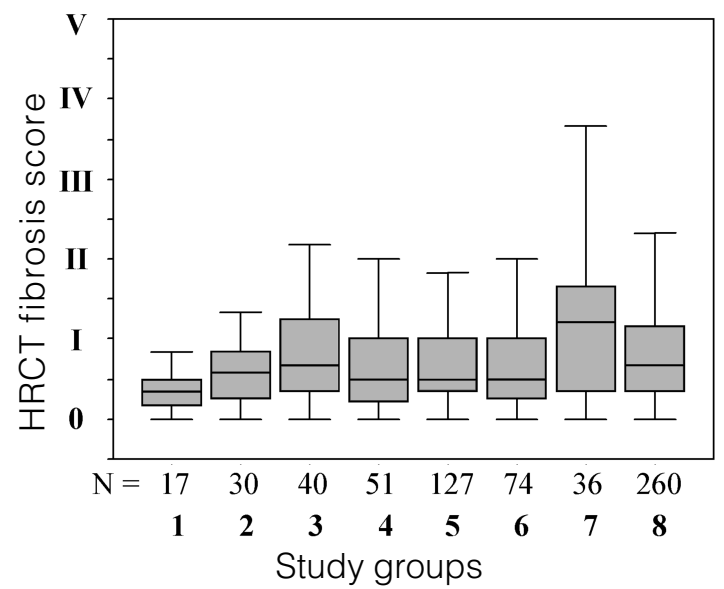

Figure 1. High-resolution computed tomography (HRCT) fibrosis score of the study groups. (Study groups: $1=$ unlikely exposed referents, 2 = possibly exposed referents, $3=$ engineers, $4=$ electricians, $5=$ carpenters, $6=$ plumbers, $7=$ insulators, $8=$ other construction workers)

by the model $\left(\mathrm{r}^{2}\right)$ was 0.86 . With the number of variables reduced to 4 , the best model (subpleural curvilinear opacities, subpleural perpendicular lines, parenchymal bands, and honeycombing) explained 0.84 of the variance, and with 3 variables (subpleural curvilinear opacities, subpleural perpendicular lines and parenchymal bands) 0.83 of the variance was explained.

The ANCOVA showed an association between the independent variables (age, gender, duration of exposure, and occupational group) and the dependent variable (the HRCT fibrosis score). The score was significantly higher for the women (mean +0.4 scores) than the men. Age (+0.02 scores/year), exposure duration (+0.005 scores/year), and occupational group were also significant predictors of the HRCT fibrosis score. The posthoc analysis of variance showed a significant difference between group 1 (unlikely exposed referents) and all the other groups and between group 7 (insulators) and all the other groups (figure 1).

\section{Consensus}

After all the images had been reviewed, the readers held a meeting on the fibrosis criteria. By comparing both images that they had agreed and disagreed on, they formed a consensus on the criteria (table 3) with standard images representing various fibrosis classes (figures $2 \mathrm{a}, \mathrm{b}, \mathrm{c}$, and d).

During the study, new cases of asbestosis had been diagnosed in groups 3-8 (our study results were not used in clinical decision making), making a total of 121 patients with the disease. The HRCT fibrosis score was significantly higher for the patients with asbestosis $(=1.60$ scores $)$ than for the other exposed workers $(=0.59$ scores).

Table 1. Observer agreements. (HRCT = high-resolution computed tomography, ILO = International Labour Office)

\begin{tabular}{lcc}
\hline Criterion & Interobserver & Intraobserver \\
\hline HRCT fibrosis score & 0.64 & 0.72 \\
Subpleural dependent opacity & 0.50 & 0.59 \\
Subpleural curvilinear opacities & 0.61 & 0.39 \\
Subpleural perpendicular lines & 0.46 & 0.55 \\
Parenchymal bands & 0.30 & 0.46 \\
Subpleural nodules & 0.20 & 0.23 \\
Honeycombing & 0.60 & 0.80 \\
Ground glass opacities & 0.23 & 0.75 \\
ILO classification & 0.73 &.$\cdot$ \\
\hline
\end{tabular}

Table 2. Correlation between the HRCT fibrosis score and the specified abnormalities. (HRCT = high-resolution computed tomography, $r=$ correlation coefficient, $r^{2}=$ coefficient of determination)

\begin{tabular}{lllr}
\hline & $r$ & $r^{2}$ & $P$ \\
\cline { 2 - 4 } A. Subpleural dependent opacity & 0.17 & $0.03<0.001$ \\
B. Subpleural curvilinear opacities & 0.60 & $0.36<0.001$ \\
C. Subpleural perpendicular lines & 0.83 & $0.70<0.001$ \\
D. Parenchymal bands & 0.59 & $0.35<0.001$ \\
E. Subpleural nodules & 0.64 & 0.42 & $<0.001$ \\
F. Honeycombing & 0.54 & 0.29 & $<0.001$ \\
G. Ground glass opacities & 0.40 & 0.16 & $<0.001$ \\
H. Emphysema & 0.10 & 0.01 & 0.014 \\
I. Other disease & 0.36 & 0.13 & $<0.001$ \\
\hline B, C, D and F combined & & 0.84 & $<0.001$ \\
B, C, and D combined & $\cdot$ & 0.83 & $<0.001$ \\
B and C combined & $\cdot$ & $0.78<0.001$ \\
H and I (confounding factors) combined &. & 0.13 & $<0.001$ \\
\hline
\end{tabular}

Table 3. Consensus criteria for fibrosis.

\begin{tabular}{|c|c|}
\hline & Criterion \\
\hline \multicolumn{2}{|l|}{ Interstitial fibrosis } \\
\hline Sufficient criterion & Honeycomb cysts \\
\hline Other fibrosis criteria & $\begin{array}{l}\text { Subpleural irregular opacities, septal } \\
\text { lines, curvilinear opacities, subpleural } \\
\text { ground glass opacity, parenchymal } \\
\text { bands }\end{array}$ \\
\hline $\begin{array}{l}\text { Other abnormalities } \\
\text { (possibly related to } \\
\text { asbestos exposure) }\end{array}$ & $\begin{array}{l}\text { Rounded atelectasis, adhesions, } \\
\text { thickening of interlobar fissures, vessel } \\
\text { or bronchial walls }\end{array}$ \\
\hline \multicolumn{2}{|l|}{ Fibrosis classes } \\
\hline Class 0 (normal finding) & Normal finding by all criteria \\
\hline Class I (subnormal finding) & $\begin{array}{l}\text { 1-2 criteria sporadically in lung } \\
\text { periphery; no honeycombing }\end{array}$ \\
\hline Class II (mild fibrosis) & $\begin{array}{l}\text { At least } 2 \text { criteria on both sides and in } \\
\text { several slices from the lung periphery } \\
\text { (distinct unilateral changes or } \\
\text { numerous other changes in exceptional } \\
\text { cases); no honeycombing }\end{array}$ \\
\hline Class III (moderate fibrosis) & $\begin{array}{l}\text { Several criteria, which extend deeper into } \\
\text { the lung (than in class II); honeycombing } \\
\text { as a general rule }\end{array}$ \\
\hline Class IV (severe fibrosis) & $\begin{array}{l}\text { Several criteria or associated findings } \\
\text { extending deep into the lung; honeycomb } \\
\text { ing; lung architectural change }\end{array}$ \\
\hline Class V (extreme fibrosis) & $\begin{array}{l}\text { Extremely severe and various fibrotic } \\
\text { changes; little normally aerated lung left }\end{array}$ \\
\hline
\end{tabular}



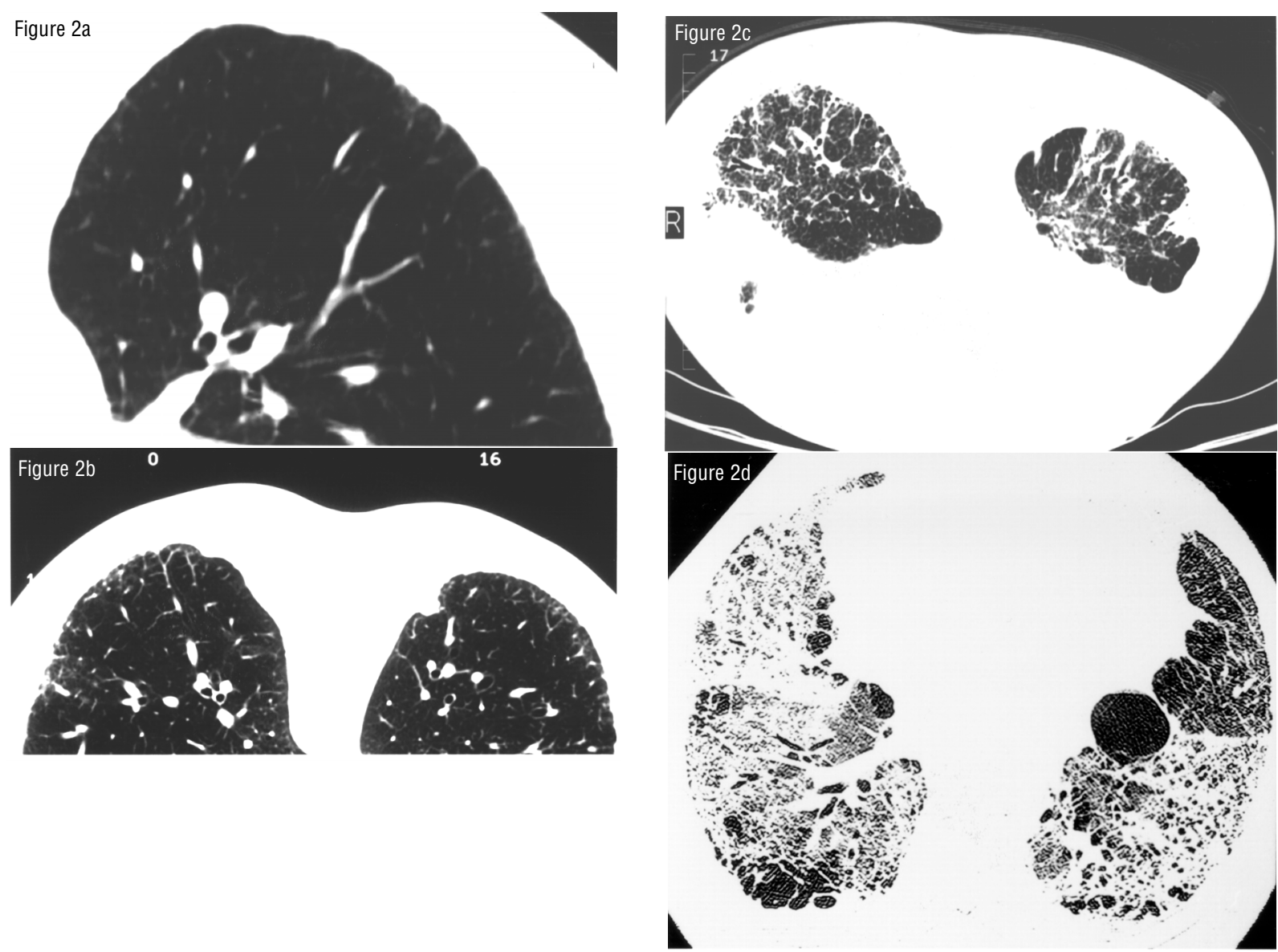

Figure 2. Example images of lung fibrosis in high-resolution computed tomography (HRCT). [a = class I (subnormal finding), $b=$ class II (mild fibrosis), $\mathrm{c}=$ classified between III and IV (moderate to severe fibrosis), $\mathrm{d}$ = class V (extreme fibrosis), patient not included in study]

\section{Analysis of the receiver-operating characteristic}

The area under the ROC curve $\left(\mathrm{A}_{1}\right)$ of the HRCT fibrosis score was $0.89\left(\mathrm{SE}_{1}=0.023\right)$ (figure 3$)$. The best cutoff point suggesting asbestosis was class I/II (out of V), at which point the sensitivity was $70 \%$, and the specificity was $91 \%$. Equal weight was given to the false positive and false negative results.

The area under the ROC curve of the ILO classification $\left(\mathrm{A}_{2}=0.76, \mathrm{SE}_{2}=0.037\right)$ was significantly lower than that of the HRCT classification $(\mathrm{P}<0.001)$. In this study, the sensitivity of the ILO classification was $51 \%$, with a specificity of $89 \%$, at the best cut-off point of 1/0. Spearman's correlation between the HRCT fibrosis score and the ILO profusion score $(\rho=0.41, \mathrm{P}<0.001)$ is shown in figure 4 with the nonparametric line of best fit.

\section{Discussion}

The classification of interstitial lung fibrosis is important when asbestosis is being diagnosed. Exact criteria are essential for the equal and fair treatment of all patients. We found a semiquantitative HRCT scoring method to be a simple and reliable method for use in the evaluation of interstitial lung fibrosis and asbestosis among asbestos-exposed workers.

Our material was a sample of Finnish workers with an asbestos-related lung or pleural disease. Unlike the exposed workers, all the referents had a malignant disease or were suspected of having a malignant disease. The reference group was also rather small when compared with the group of exposed workers, but it would have been unethical to expose large numbers of healthy referents to the extra radiation. High tube currents were used to optimize the image resolution because studies on low-dose HRCT were few at the time of our study (26). The effective radiation dose in HRCT is higher than in chest radiography (27), but with the use of a lowdose technique (26) and a limited number of slices, it can be considerably diminished. Asbestos exposure could not be ruled out for $61 \%$ of our referents even though they had reported none. Workers seem to be poorly aware of their asbestos exposure, and specific questions were needed to work out the answer. Total 
blindness could not be accomplished in the image analysis between the exposed workers and the referents because of different techniques. However, the main differences with respect to the HRCT fibrosis score did not occur between these identifiable groups. Because the comparison of HRCT with chest radiographs has already been studied extensively earlier $(3,8,18)$, all the radiographs were not scored according to the ILO classification.

Some CT findings showed a low interobserver agreement, while the intraobserver agreement was higher. This difference may reflect differences in the threshold values recognized as pathological (subpleural nodules, ground glass opacities) or lacking standards that define to which group a single finding belongs (eg, subpleural perpendicular lines versus small parenchymal bands). In this study the interobserver agreement for the ILO classification was better than that for the HRCT fibrosis score. The lower sensitivity of our ILO classification points to a high number of false negative radiographs, and the normal findings were probably well agreed on. The opposite has also been stated in that Bégin et al (8) and Talini et al (28) achieved a better agreement for conventional CT and HRCT.

Eighty-six percent of the variation in the HRCT fibrosis score was explained by the scored lung findings. It was concluded that we had paid attention to the correct fibrosis findings. Fibrosis could be well classified even by using 3-4 scored findings. Confounding factors (emphysema and other diseases) did not disturb the classification severely. A limited number of abnormalities determining fibrosis can be included in future classification forms.

Both age and occupational group were significant predictors of fibrosis, as assumed. This kind of age effect has also been found for the ILO classification (29). Parenchymal fibrosis seems to indicate heavy exposure to asbestos more clearly than pleural plaques, which showed no significant differences between these occupational groups (unpublished work by Tiitola et al). The women had a significantly higher average HRCT fibrosis score than the men. The mean age of the women (68 years) was higher than that of the men (62 years), but the high age should not account for such a difference. Smoking habits or body mass index (BMI) did not offer a solution either. Whether it was merely a chance finding due to the small number of women (only 11 in this study) or whether there are other unrecognized factors involved is not clear, and additional research is required in this respect. Differences in the degree of inspiration during the HRCT examination may also have confounded the estimation of fibrotic changes.

According to our results, asbestosis can be reliably diagnosed with HRCT (17). Comparison of the ROC curves of the HRCT and ILO classifications indicated

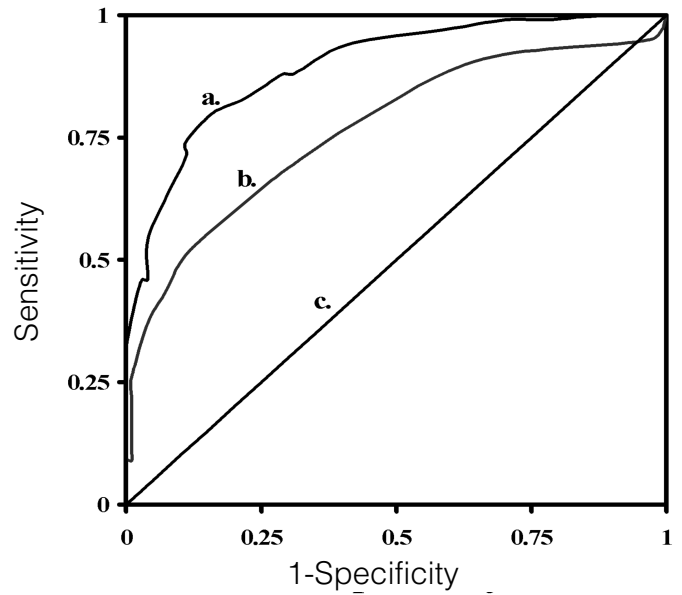

Figure 3. Curves of the receiver operating charachteristic (ROC) classification. $[\mathrm{a}=$ high-resolution computed tomography (HRCT) fibrosis score, $b=$ classification of the International Labour Office (ILO), $c=0.5$ reference line]

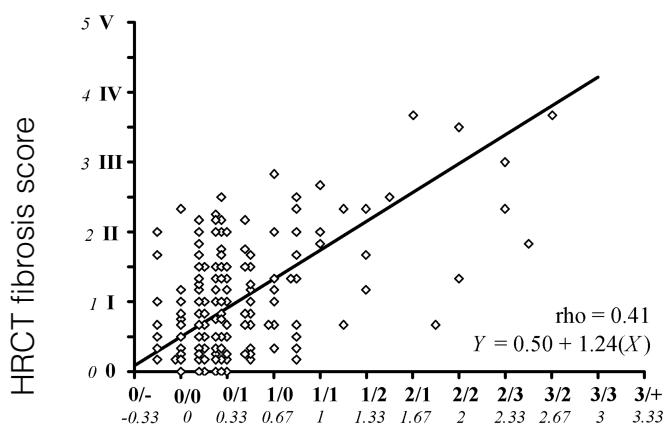

ILO classification

Figure 4. Correlation of the high-resolution computed tomography (HRCT) fibrosis score (mean of 3 readers) and the classification of the International Labour Office (ILO) (mean of 2 readers). The numbers in italics are the values used in the calculations. (diagonal line $=$ nonparametric regression line)

that the HRCT fibrosis score is a better method for this purpose. The sensitivity ( $70 \%$ versus $51 \%$ ) of our method was higher. The class I/II diagnostic of asbestosis in the HRCT classification corresponds approximately to $1 / 0$ in the ILO classification (figure 4). The correlation between the 2 classifications was rather low ( $\rho=0.41$ ), as could be expected due to the superiority of the HRCT based on our ROC analysis and supported by the literature (19).

In conclusion, we found a semiquantitative HRCT scoring system with written definitions and reference images to be a simple, reliable, and reproducible method for classifying lung fibrosis. Our results could be of use when an international HRCT classification is designed for occupational lung disease. 


\section{Acknowledgments}

The authors wish to thank Simo Kaleva, MSc, for selecting the patients for the ILO classification. We would also like to thank Drs Hannu Lehtola and Kaarina Huuskonen for the patient interviews.

\section{References}

1. International Labour Office (ILO). Guidelines for the use of ILO international classification of radiographs of pneumoconioses. Geneva: ILO, 1980. Occupational safety and health series 22 , revised edition.

2. American Thoracic Society (ATS). The diagnosis of nonmalignant diseases related to asbestos. Am Rev Respir Dis 1986;134:363-8.

3. Friedman AC, Fiel SB, Fisher MS, Radecki PD, Lev-Toaff AS, Caroline DF. Asbestos-related pleural disease and asbestosis: a comparison of $\mathrm{CT}$ and chest radiography. Am J Roentgenol 1988;150:269-75.

4. Koskinen K, Zitting A, Tossavainen A, Rinne J-P, Roto P, Kivekäs $\mathbf{J}$ et al. Radiographic abnormalities among Finnish construction, shipyard and asbestos industry workers. Scand J Work Environ Health 1998;24:109-17

5. Rockoff SD, Schwartz A. Roentgenographic underestimation of early asbestosis by International Labor Organization Classification: analysis of data and probabilities. Chest 1988; 93:1088-91.

6. Aberle DR, Gamsu G, Ray CS, Feuerstein IM. Asbestosrelated pleural and parenchymal fibrosis: detection with highresolution CT. Radiology 1988;166:729—34.

7. Akira M, Yokoyama K, Yamamoto S, Higashihara T, Morinaga K, Kita N et al. Early asbestosis: evaluation with high-resolution CT. Radiology 1991;178:409-16.

8. Bégin R, Ostiguy G, Filion R, Colman N, Bertrand P. Computed tomography in the early detection of asbestosis. Br J Ind Med 1993;50:689-98.

9. Harkin TJ, McGuinness G, Goldring R, Cohen H, Parker JE, Crane $\mathrm{M}$ et al. Differentiation of the ILO boundary chest roentgenograph $(0 / 1$ to $1 / 0)$ in asbestosis by high-resolution computed tomography scan, alveolitis, and respiratory impairment. J Occup Environ Med 1995;38:46-52.

10. Oksa P, Suoranta H, Koskinen H, Zitting A, Nordman H. HRCT in the early detection of asbestosis. Int Arch Occup Environ Health 1994;65:299-304.

11. Soulat JM, Lauque D, Esquirol Y, Déprés M, Giron J, Claudel R, et al. High-resolution computed tomography abnormalities in ex-insulators annually exposed to asbestos dust. Am J Ind Med 1999;36:593-601.

12. Gevenois PA, De Vuyst P, Dediere J, Vande Weyer R, Struyven J. Conventional and high resolution CT in asymptomatic asbestos-exposed workers. Acta Radiol 1994;35:226-9.

13. Neri S, Boraschi P, Antonelli A, Falachi F, Baschieri L. Pulmonary function, smoking habits, and high resolution computed tomography (HRCT) early abnormalities of lung and pleural fibrosis in shipyard workers exposed to asbestos.
Am J Ind Med 1996;30:588—95.

14. Schwartz DA. The clinical relevance of asbesots-induced pleural fibrosis. Ann N Y Acad Sci 1991;643:169—77.

15. Ahn CS, Kim SJ, Oh JS, Park HJ, Kim HJ, Ahn CM, et al. Pulmonary asbestosis: radiologic-pathologic brief report. Yonsei Med J 1997;38:323—6.

16. Akira M, Yamamoto S, Yokoyama K, Kita N, Morinaga K, Higashihara T, et al. Asbestosis: high-resolution CT - pathologic correlation. Radiology 1990;176:389—94.

17. Ren H, Lee DR, Hruban RH, Kuhlman JE, Fishman EK, Wheeler PS, et al. Pleural plaques do not predict asbestosis: high-resolution computed tomography and pathology study. Mod Pathol 1991;4:201-9.

18. Al Jarad N, Wilkinson P, Pearson MC, Rudd RM. A new high resolution computed tomography scoring system for pulmonary fibrosis, pleural disease, and emphysema in patients with asbestos related disease. Br J Ind Med 1992; 49:73-84.

19. Gamsu G, Salmon CJ, Warnock ML, Blanc PD. CT quantification of interstitial fibrosis in patients with asbestosis: a comparison of 2 methods. Am J Roentgenol 1995;164:638.

20. Hartley PG, Galvin JR, Hunninghake GW, Merchant JA, Yagla SJ, Speakman SB, et al. High-resolution CT-derived measures of lung density are valid indexes of interstitial lung disease. J Appl Physiol 1994;76:271-7.

21. Kraus T, Raithel HJ, Lehnert G. Computer-assisted classification system for chest X-ray and computed tomography findings in occupational lung disease. Int Arch Occup Environ Health 1997;69:482-6.

22. Murray KA, Gamsu G, Webb WR, Salmon CJ, Egger MJ. High-resolution computed tomography sampling for detection of asbestos-related lung disease. Acad Radiol 1995; $2: 111-5$.

23. Abramson JH, Gahlinger PM. Computer Programs for Epidemiologists: PEPI Version 3.01. Llanidloes, Powys (Wales): Brixton Books, 1999.

24. Hanley JA, McNeil BJ. A method of comparing the areas under receiver operating characteristic curves derived from the same cases. Radiology 1983;148:839—43.

25. Sprent P. Applied nonparametric statistical methods. 2nd ed. London: Chapman \& Hall, 1993.

26. Majurin M-L, Varpula M, Kurki T, Pakkala L. High resolution CT of the lung in asbestos-exposed subjects: comparison of low-dose and high-dose HRCT. Acta Radiol 1994; $35: 473-7$.

27. van der Bruggen-Bogaarts BA, Broerse JJ, Lammers JW, van Waes PF, Geleijns J. Radiation exposure in standard and high-resolution chest CT scans. Chest 1995;107:113-5.

28. Talini D, Paggiaro PL, Falaschi F, Battolla L, Carrara M, Petrozzino M, et al. Chest radiography and high resolution computed tomography in the evaluation of workers exposed to silica dust: relation with functional findings. Occup Environ Med 1995;52:262-7.

29. Zitting AJ. Prevalence of radiographic small lung opacities and pleural abnormalities in a representative adult population sample. Chest 1995;107:126-31.

Received for publication: 25 April 2000 